\section{Ruptured ectopic pregnancy after a decline in chorionic gonadotropin}

\section{Laurie Montgomery Irvine}

J R Soc Med 2006;99:90

The advent of automated assays for beta human chorionic gonadotropin $(\beta$-hCG) has made expectant management a realistic option in selected cases of suspected ectopic pregnancy.

\section{CASE HISTORY}

A woman of 37, a multigravida, was referred because of continuous and increasingly heavy bleeding since her last menstrual period two weeks earlier and worsening leftsided pelvic pain for the past four days. She had been using a progesterone-only pill for contraception. A home urinary pregnancy test had been positive. On examination she was haemodynamically stable; she had lower abdominal tenderness on the left side without peritonism and a left adnexal mass was felt per vaginam. The diagnosis was in doubt but she was judged to have an intrauterine pregnancy. A transvaginal scan showed a thickened endometrium and the possibility of a right simple cyst, there was also some free fluid in the pouch of Douglas. Serum $\beta$-hCG was $123 \mathrm{iu} / \mathrm{mL}$. She was followed up as an outpatient, and two further $\beta$-hCGs two days apart were 62 and $21 \mathrm{iu} / \mathrm{mL}$; she was due to have a repeat scan at one week. Six days after her initial presentation severe lower abdominal pain developed and she was admitted to hospital. At diagnostic laparoscopy she was found to have a leaking left fimbrial ectopic pregnancy; she also had a right simple ovarian cyst. Partial salpingectomy was performed laparoscopically, and the ectopic pregnancy was confirmed histologically.

\section{COMMENT}

Ectopic pregnancy remains an important cause of maternal deaths in the UK; there were 11 fatal cases in the last triennial report. ${ }^{1}$ This is despite the advent of a rapid qualitative urine $\beta$-hCG assay which if negative virtually excludes ectopic pregnancy. Other investigations include a quantitative serum $\beta$-hCG assay which can be used with transvaginal scanning as part of an algorithm in suspected ectopic pregnancy. In the present case the low and falling $\beta$ hCG suggested the pregnancy was unlikely to be ectopic. ${ }^{2}$ Even if a pregnancy is indeed ectopic, a falling $\beta$-hCG points to a self-limiting form of pregnancy that requires no intervention. ${ }^{3}$

Review of the published work indicates a consensus that, whatever the site of pregnancy, a falling $\beta$-hCG concentration justifies expectant management. ${ }^{4}$ Moreover, women whose ectopic pregnancy resolved spontaneously have been found to have lower initial $\beta$-hCGs (mean $246 \mathrm{iu} / \mathrm{L}$ ) than those who required surgery (mean $628 \mathrm{iu} /$ L). ${ }^{5}$ Against this must be set rare cases in which a decline in $\beta$-hCG was followed by tubal rupture. ${ }^{6}$ Possible mechanisms in these cases are blood-vessel erosion by a surviving clump of trophoblastic tissue (Padwick ML, personal communication) or pressure necrosis from an intraluminal clot. ${ }^{6}$

The special feature of the present case is the exceptionally low level at which symptoms of rupture developed $(21 \mathrm{iu} / \mathrm{L})$; the lowest previously reported was $97 \mathrm{iu} / \mathrm{L}$. For clinicians the message is that, when expectant management is decided upon, the patient requires regular hospital review and the $\beta$-hCG must be followed down to 'non-pregnant' levels. ${ }^{7}$

\section{REFERENCES}

1 Confidential Enquiry into Maternal and Child Death. Why Mothers Die. London: RCOG Press, 2004

2 Dart RG, Mitterando J, Dart LM. Rate of change of serial beta human chorionic gonadotrophin values as a predictor of ectopic pregnancy in patients with indeterminate transvaginal scan findings. Ann Emerg Med 1999;34:707-10

3 Ankum WM. Diagnosing suspected ectopic pregnancy. BMJ 2000;321:1235-6

4 Ankum WM, Van der Veen F, Hamerlynck JVT, Lammes FB. Suspected ectopic pregnancy-what to do when human chorionic gonadotrophin levels are below the discriminatory zone. $J$ Reprod Med 1995;40:525-8

5 Elson J, Tailor A, Banerjee S, Salim R, Hillaby K, Jurkovic D. Expectant management of tubal ectopic pregnancy: prediction of successful outcome using decision tree analysis. Ultrasound Obstet Gynecol 2004;23:552-6

6 Gretz E, Quagliarello J. Declining serum concentrations of the $\beta$ subunit of human chorionic gonadotrophin and ruptured ectopic pregnancy. Am J Obstet Gynecol 1987;156:940-1

7 Irvine LM, Padwick M. Serial serum HCG measurements in a patient with an ectopic pregnancy: a case for caution. Hum Reprod 2000; 15:1646-7 